\title{
OBSERVATION ON CREATIVITY AND SPATIAL VISUALISATION SKILLS OF GRAPHIC ARTS' STUDENTS
}

\author{
Helena Gabrijelčič Tomc (D), Tanja Nuša Kočevar (D) \\ University of Ljubljana, Faculty of Natural Sciences and Engineering, Department of Textiles, \\ Graphic Arts and Design, Chair of Information and Graphic Arts Technology, Ljubljana, Slovenia
}

\begin{abstract}
The aim of our research was to discover whether education in 3D computer graphics and visualisation can improve students' spatial visualisation skills and how the complex project as a design and synthesis of a 3D animation influences students' creativity. Spatial visualisation skills are extremely valuable in various professions, including graphic design and engineering, where 3D modelling and visualisation is becoming increasingly important for the qualitative execution of professional projects. Scientists define two types of three-dimensional skills, spatial visualisation and spatial orientation, where visualisation is understood as the ability to mentally rotate, flip and flip over presented images, while spatial orientation describes the ability to recognise the position or direction of objects in space. Creative process is defined as a sequence of thoughts and actions that lead to original and appropriate productions. The creative process can be discussed on two levels, i.e. macro and micro level with the related phases of the creative process: orientation, preparation, complementary stages after preparation, incubation, idea generation, production.

The facultative course Advanced computer 3D graphic and visualisations is taught in the 2nd level studies of Graphic and interactive communication. Through project work, students are encouraged to use their creativity and imagination to create a visually attractive 3D animation that is also interesting in terms of content and in which they can convey the story they want to tell. For this reason, we often held individual sessions in which the teachers made profound corrections to the students' work and made suggestions for the further development of their projects. Experimental methods were: Questionnaires for self-assessment of the creativity process, whereby the students also interpreted their creative process with an illustration and the spatial visualisation test before and after the course. Regular evaluation of their project work with regard to the entire design process, i.e. 3D content creation, planning, technical approach and production, were also carried out. Results of the analysis present an interesting insight in students' creative process, spatial ability and comprehension of 3D computer graphic that could be considered as teaching/learning guidelines in the coming academic years.
\end{abstract}

Key words: creativity, spatial visualisation skills, 3D content creation, education, graphic arts

\section{INTRODUCTION}

Spatial intelligence is the ability to perceive the visual world accurately and the capacities to transform these perceptions. The elementary operation upon which other aspects of spatial intelligence are based is the ability to perceive a form or an object. Spatial intelligence is characterized as a very important skill that has an immense impact on our everyday life as it involves our ability to navigate from one place to another, to understand drawings, charts, it is the ability to visualise objects from different angles, ability to recognise faces, scenes and fine details and so on (Gardner, 2011). Spatial ability is an important component of spatial intelligence and is defined as "the ability to mentally manipulate, rotate, twist or invert pictorially presented stimuli" by an author McGee (McGee, 1979). Spatial ability is by authors Linn and Petersen (Linn et al, 1985) divided in three categories: spatial perception, mental rotation and spatial visualization. Spatial visualisation is "the ability to mentally manipulate, rotate, twist, or invert pictorially presented stimulus objects." (McGee, 1979). This ability helps us to imagine links between reality and the model of that reality that is abstracted (Alias et al, 2002). Spatial Visualisation refers to the ability to manipulate complex spatial information and to mentaly manipulate 2D and 3D objects. This skill can be assessed using tasks such as mentally folding paper and rotating objects, and to imagine the change of objects and shapes (Roslan and Ahmad, 2017). Spatial visualisation skills are extremely valuable in a variety of professions, including graphic design and engineering. These jobs require excellent 2D and 3D visualisation skills, which are important for the qualitative implementation of highly professional projects (Patkin and Dayan, 2013). Research has shown that a person's spatial visualisation skills are very important predictors of their ability to successfully use computers to perform database manipulations 
(Norman, 1994), and are related to his or her ability to effectively learn and successfully work in a computer-based 3-D design environment (Sorby, 2000).

However, it was discovered that spatial visualisation skills can improve and the results can be tested. There are several tests to evaluate different types of spatial visualisation skills. In our research we have used some of them, such as Picture rotation test (PRT), Differential Aptitude Test: Space Rotation, (DAT:SR), The Punched Holes Test (Paper Folding Test) and others.

Designing and creating 3D animations requires a wide range of skills from students, with creativity and spatial awareness being more important. Therefore, we have investigated the connection between both in our research.

The process of creativity has often been discussed by various researchers in the past. The definitions of researchers differ slightly, but the most important research certainly has common insights into the creative process, as it is defined as a sequence of thought processes (including mental processes) and activities leading to unique and purposeful production. Researchers generally describe two levels of the creative process, namely the micro and macro levels (Botella et al, 2018). The macro level comprises the phases or steps of the creative process, while the micro level deals with the mechanisms that take place in the background of the creative process, as well as the so-called divergent and convergent or alternating thinking and engagement (Botella et al, 2018).

Here we can only mention a few typical models of the creative process that have been published in the past decades, ranging from the definition of a minimum of three phases of the creative process to a maximum of 8 phases. At the end of the 20th century, according to their analyzes, the author Carson (Carson, 1999) listed 9 phases, i.e. preparation, concentration, incubation, ideation, insight, verification, elaboration, production, while the authors of Runco and Dow (Runco and Dow, 1999) identified only 3 important phases of a typical creative process in the same year, i.e. problem finding, incubation, evaluation. In 2011, Botella (Botella et al, 2011) and co-authors published a scheme for the creative process of art students, which summarizes up to 9 steps in a comprehensive way, i.e. preparation, concentration, incubation, ideation, insight, verification, planification, production and validation, and soon after presented a scheme for artists with fewer steps, which were also named quite differently (Botella et al, 2013), i.e. idea or vision, documentation, reflection, first sketches, testing, provisional objects and series.

Research proves that differently defined creativity models can be applied to different areas (art, business), but at the same time are defined differently depending on the professional area. Botella et al. performed testing of professional artists (Botella et al, 2013) and students (Botella et al, 2018), and found out that professionals with many years of experience carry out the creative process within some established phases that suggest routine. That was not the case with the students. When the students were interviewed and invited to describe their creative process and name the stages of their creative process there were no signs of established practices, instead a trend of very individual, personal experience was detected. The named stages and their description were then compared with the already existing models giving to the researchers new insight about the creative process of students of visual graphic arts. The results of the analysis identified 17 stages (immersion, reflection, research, inspiration, illumination, trials, assembly, ideation, selection, techniques, specification, realisation, finalization, judgment, presentation, break and withdrawal), which can be used as guides for teachers, but at the same time invite them to further observe students and the phases of creative work that students carry out between specific tasks and project work of the study process.

\subsection{Aim of the research}

The aim of the research was to analyse and define the creative process and its correlation with the spatial ability of graphic arts students attending facultative course "Advanced 3D computer graphic and visualisation" at 2nd level degree studies of university study programme of Graphic and interactive communication. From the analysis it can be discovered whether the education in 3D computer graphics and visualisation can improve students' spatial visualisation skills, whether the studying of 3D graphic can improve the conception and definition of the creative process, reveal how students are personally involved in the process, what level of abstraction they use in the process, and how successfully the students carry out a practical project and acquire skills for relevant 3D modeling, animation and visualization results. 


\section{METHODS}

Seven (7) master degree study students participated in our research. Before and after the semester they were asked to fill in the questionnaire about their understanding of the creative process and to complete the spatial visualisation test.

Methodology included:

- questionnaire before and after the semester (project work) about the creative process, its phases, self-evaluation of knowledge in the 3D field (before the semester, students physically wrote the answers, and after the semester, in an online form)

- $\quad$ students were asked to define their creative process in words and with a drawing (before semester: on a white A4 sheet of paper, using any drawing tool; after semester: in on-line form); students were asked to draw their creative process twice, firstly together with the test on paper and secondly when they had to fill in the on-line form

- $\quad$ spatial ability testing (before and after the semester/project work)

- numerical evaluation of the project work including 3D computer graphic (grading technical, content and visualization level)

- semantic evaluation, analysis and correlation of written and drawn information that define the creative process

- definition of the categories based on written and drawn information (Table 2): Stages defining creative process - how many stages were defined by the student; Personal involvement - how the student expressed him/herself in terms of identification and personal involvement in the definition of the creative process and the indication of its phases (whether he/she expressed him/herself in the 1st person singular, in the passive form, etc.); Number of adjectives - how descriptively (with adjectives) the student expressed himself in the definition of the creative process and its phases; Level of abstraction - what degree of abstraction was identified in the student's descriptions and drawings; Difference of expression in physical and on-line form - what difference was recognized in the written and descriptive expression of the student when the latter used writing on paper compared to solving an on-line questionnaire; Correlation between written description and $3 D$ product - what difference was recognized between the search and outline definitions and explanations of the creative process and the final product of 3D computer graphics (3D modeling, visualization and animation); Grade of the 3D knowledge, 3D work - assessment of knowledge of the field given by the student with self-evaluation at the beginning of the semester and assessment of the final (given by the mentors) product in technical visualization and content sense after the submission of the final product; Spatial visualisation test - number of correctly solved tasks, where 4 tasks in the beginning and 9 tasks in the end of semester were performed including Paper Folding Test, The Surface Development Test, Paper Form Board Test, Differential Aptitude Test: Space Relations, Picture Rotation Test.

- Quantification of semantic evaluation - the categories defined from the written, descriptive and intimidated material of the students were numerically or descriptively defined (by the number of words used, the number of adjectives, the descriptive assessment of the correlation, i.e. low, medium, high)

- evaluation of students' visualisations of creative process was also performed that allow the explanation of semantic dimensions. 


\section{RESULTS}

In the results we present the students' answers to the questionnaire and in the discussion the analysis is presented.

The students answered all questions and visualised their perception of the creative process before and after the semester. Before the semester they were asked to write answers on paper and after the semester the test was done online, with visualisation on paper. Table 1 shows the answers to the questionnaire of a representative student (Student 5) together with a visualisation of the creative process before and after the semester.

Table 1: Student's answers to the questions before and after the semester

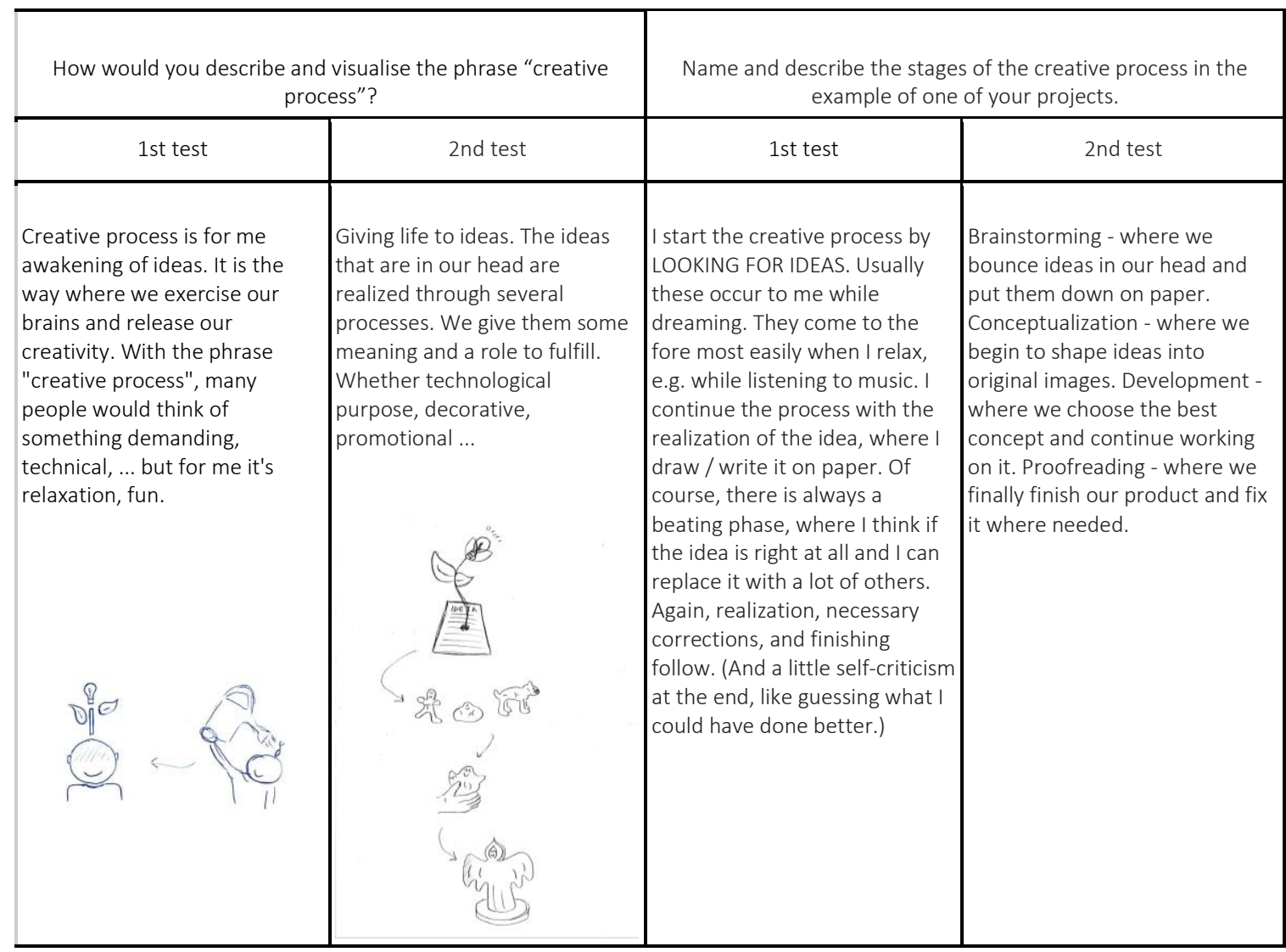

In Table 2 the results of quantification of semantic evaluation of the defined categories are presented. 


\begin{tabular}{|c|c|c|c|c|c|c|c|c|c|c|c|c|c|}
\hline \multirow{2}{*}{$\begin{array}{l}\text { Categories } \\
\\
\begin{array}{l}\text { Student, } \\
\text { before/ } \\
\text { after } \\
\text { semester }\end{array}\end{array}$} & \multicolumn{2}{|c|}{$\begin{array}{l}\text { Stages defining } \\
\text { creative process }\end{array}$} & \multicolumn{2}{|c|}{$\begin{array}{l}\text { Personal involvement; } \\
\text { writes in ... }\end{array}$} & \multicolumn{2}{|c|}{$\begin{array}{l}\text { Adjectives (No. of } \\
\text { adjectives) }\end{array}$} & \multicolumn{2}{|c|}{$\begin{array}{l}\text { Level of } \\
\text { abstraction }\end{array}$} & \multirow[b]{2}{*}{$\begin{array}{l}\begin{array}{l}\text { Difference } \\
\text { of } \\
\text { expression }\end{array} \\
\text { in physical } \\
\text { and on- } \\
\text { line form }\end{array}$} & \multirow[b]{2}{*}{$\begin{array}{l}\begin{array}{l}\text { Correlation } \\
\text { between }\end{array} \\
\text { written } \\
\text { description } \\
\text { and 3D } \\
\text { product }\end{array}$} & \multicolumn{2}{|c|}{$\begin{array}{l}\text { Grade of the 3D knowledge, 3D } \\
\text { work }\end{array}$} & \multirow[t]{2}{*}{$\begin{array}{l}\text { Spatial } \\
\text { ability } \\
\text { before, } \\
\text { after }\end{array}$} \\
\hline & before & after & before & after & $\begin{array}{l}\text { befor } \\
\text { e }\end{array}$ & after & before & after & & & $\begin{array}{l}\begin{array}{l}\text { before } \\
\text { semester - } \\
\text { selfevalu. }\end{array} \\
\text { (1-none } 5 \\
\text { excellent) }\end{array}$ & $\begin{array}{l}\text { grade of the } \\
\text { results }\end{array}$ & \\
\hline 1 & 13 & 5 & $\begin{array}{l}1 \text { st } \\
\text { person, } \\
\text { singular }\end{array}$ & passive & 1 & 2 & no & low & high & very high & 2 & $\begin{array}{l}\text { content }=9 \\
\text { technical }=9 \\
\text { visual }=9\end{array}$ & $\begin{array}{l}4 / 4 \\
4 / 9\end{array}$ \\
\hline 2 & 11 & 11 & $\begin{array}{l}\text { 2nd } \\
\text { person, } \\
\text { singular }\end{array}$ & $\begin{array}{l}\text { 2nd } \\
\text { person, } \\
\text { singular }\end{array}$ & 0 & 0 & no & no & no & very high & 3,5 & $\begin{array}{l}\text { content }=8 \\
\text { technical }=9 \\
\text { visual }=8\end{array}$ & $4 / 9$ \\
\hline 3 & 6 & 4 & $\begin{array}{l}\text { 1st } \\
\text { person, } \\
\text { singular }\end{array}$ & $\begin{array}{l}\text { 1st } \\
\text { person, } \\
\text { plural }\end{array}$ & 4 & 2 & high & low & high & very high & & $\begin{array}{l}\text { content }=10 \\
\text { technical=10 } \\
\text { visual=10 }\end{array}$ & $6 / 9$ \\
\hline 4 & 8 & 8 & $\begin{array}{l}\text { 1st and } \\
\text { 2nd } \\
\text { person, } \\
\text { singular }\end{array}$ & passive & 8 & 1 & no & no & high & very high & 3 & $\begin{array}{l}\text { content }=10 \\
\text { technical }=8 \\
\text { visual }=8\end{array}$ & $7 / 9$ \\
\hline 5 & 11 & 5 & $\begin{array}{l}\text { 1st } \\
\text { person, } \\
\text { singular }\end{array}$ & $\begin{array}{l}\text { 1st } \\
\text { person, } \\
\text { plural }\end{array}$ & 5 & 6 & high & middle & no & very high & 4 & $\begin{array}{l}\text { content }=10 \\
\text { technical=10 } \\
\text { visual=10 }\end{array}$ & $7 / 9$ \\
\hline 6 & 12 & 6 & $\begin{array}{l}\text { 2nd } \\
\text { person, } \\
\text { singular } \\
\text { and } \\
\text { passive }\end{array}$ & $\begin{array}{l}\text { 2nd } \\
\text { person, } \\
\text { singular } \\
\text { and } \\
\text { passive }\end{array}$ & 7 & 1 & $\begin{array}{l}\text { middl } \\
\text { e }\end{array}$ & middle & high & low & 3 & $\begin{array}{l}\text { content }=10 \\
\text { technical=10 } \\
\text { visual=10 }\end{array}$ & $7 / 9$ \\
\hline 7 & 10 & 6 & $\begin{array}{l}\text { 1st } \\
\text { person, } \\
\text { plural } \\
\text { and } \\
\text { passive }\end{array}$ & $\begin{array}{l}\text { 3rd } \\
\text { person, } \\
\text { plural } \\
\text { and } \\
\text { passive }\end{array}$ & 5 & 2 & low & no & high & low & 3,5 & $\begin{array}{l}\text { content }=8 \\
\text { technical=7 } \\
\text { visual }=8\end{array}$ & $7 / 9$ \\
\hline
\end{tabular}

\subsection{Analysis of written and visual results}

Student 1: At the beginning of the semester, the student visualises the creative process with a strict continuation of the process that she has determined through the numbering. The process is illustrated with variations of the light bulb, a well-known symbol of the representation of ideas. The visualisation does not contain any surprising or unconventional representation. Personal participation is represented by the symbolic drawing of a person at the beginning of the drawn scheme. The visualisation after the semester contains more pictures and details and shows the process with concretization. The drawing is more precise and defined, but without the person.

Analysis: At the beginning the student ties in the written and drawn description of the creative process without inventiveness to what is known and learned. During the study process, the creative 
expressiveness was slightly developed and also supported by improved technical knowledge. The cognitive and technical part is expressed more than emotional, although the personal style is developed and updated through the process. The spatial visualisation skills are not high.

Student 2: In the first visualisation representation of creativity contains many images created and connected by smooth, curved continued lines that loop from one complex image to another. Most of the images are associated with a digital process; variations of a screen, mouse, printer and various outputs. In the beginning and in the end of the line there are people who are closely connected to this process. The second pencil drawing is very subtle, almost invisible, the student used the whole format, as in the first visualisation. The lines are straight, completely different from the first case. Drawing is not as attractive and innovative as the first one and without any creative approach to the medium.

Analysis: The student before and after the study process describes her creative process in detail, especially about technical aspects. She writes about many phases of the process and writes in the 2 nd person singular, impersonal. There are almost no adjectives in the description and no emotional involvement. We also notice no abstractness in the description, just like in the final result - the animation. During the design process, the student tried to find her own expression in the visual style by constantly changing it, looking for a safe way to complete the task. The spatial visualisation skills are not high.

Student 3: The first drawing is very abstract, as a scheme with many arrows showing the dynamics of the process. The visualisation spreads out over the whole format, it is very bold and very assertive, but very casual. The second visualisation contains bulbs / symbols to show ideas that are incorporated into and stimulate the creative process. The drawing is still dynamic and bold, with many differently curved lines, mostly pointing upwards, showing the liveliness of the process and pointing to some developmental results, which are represented by pictures of squares similar to screens or sheets of paper. The drawing is more precise than the first and more determined.

Analysis: At the beginning of the study process the student does not use words that would show personal commitment. After the process, she writes in the singular first-person, which shows a more personal and emotional connection with the process. She describes the creative process after the process with more phases and uses many more adjectives that show a higher abstractness. All this can be related to the result, which shows a great expansion of abstract thinking in the use of visual and auditory expressions to realise ideas and to convey an emotional relationship to those ideas. The visual skills are slightly better.

Student 4: The subtle pencil drawing shows phases of the process, connected with straight lines, which end with arrows in the first drawing. The fully detailed initial image, which shows an imaginative person in a cloud, turns into less detailed images during the process and ends in a simplified illustration showing a simple silhouette. The second drawing shows a very technical approach with mathematical equations and digital tools involved in the process. In the first drawing the student includes tools like brushes and a palette, while in the second drawing she mainly shows computers.

Analysis: After the study process, the student describes fewer phases of the creative process. In the beginning she writes descriptions in the first person plural or in the second person singular, after the course she writes completely impersonal. In the first test she uses adjectives like creative, innovative, free, in the second test she uses only the adjective creative. There is no abstractness, and in the second, digital test, she describes rather stingy. The correlation between description and result is high, great ambitions and ideas were not realized.

Student 5: Attentively drawn first image, consisting of two images to be read from right to left, indicated by the curved arrow, shows a person with his thoughts or attitudes towards the process. This is shown using familiar shapes in atypical situations to explain the new concept. The visualisation expresses humour and inventiveness. The second drawing shows more phases and also conveys humour and a special attitude towards the process.

Analysis: The student describes his creative process in a very poetic and intimate way with a lot of imagination in the first person singular. After the course he uses more precise phrases that conceptualise the process, he uses the first person in the plural. The student goes from dreaming, thinking, contemplating... through conceptualization to a more structured way of thinking and observing. Great correlation between the process he describes and the end result. The visualisation is also very emotionally coloured.

Student 6: The representation of the creative process is drawn continuously, with many curved arrows and symbolic images that resemble real life and show positive emotions during the process. The visualisation tries to be very narrative, with images that tell a personal story related to the process. The visualisation is drawn with ease, but decisively, the composition takes up a whole picture format. The second drawing shows the process and the attitude towards it with various well-known symbols, almost 
emoticons, there is less originality without personal ideas, without concretization. The drawing also takes up a whole format and is decisive, bright and dynamic.

Analysis: In the first test, the student describes the creative process with many phases, very abstractly with stimulating, demanding words. The description of the process after the course is limited and without emotions, rather cognitive, third person singular or in general in the third person. There is less correlation between description and results, whose quality goes beyond the description and visualisation of the mere creative process.

Student 7: The visualisation of the creative process is shown with numbered steps, horizontally in one line with known images. At the beginning of the line a person is drawn twice, first as an interaction with the outside world and secondly as a person with inner activity. It is drawn with many short, broken lines, with one person having almost the same part in the process as a tool. The student uses only a small part of the paper format and does not show much creativity in visualisation. She did not give us the second visualisation.

Analysis: The description of the creative process is very technical, in the first person plural in the second test even in the third person plural. The description is limited, with general adjectives without emotional imprint. In the second test, after the course, the student added adjectives with more content. Abstractness is noticeable in the first description of the process, in the second test there is no abstractness and the creative process is described with fewer phases. The correlation between the description and the result is low. The student did not put much effort into the work and there were no good results. She started with a good idea to combine sound and image and the process ended in an animation without appealing content or with personal emotions. There was no creative intervention in the process, only automatic tools were used to perform the task.

\section{DISCUSSION}

From the results obtained, we can summarize, similar to the reference research (Botella et al, 2018), that the creative process of the students of the elective subject 3D computer graphics is very individual and personal. The methodology of the present research is not based on established evaluation tools and procedures, instead, it introduces a specific evaluation approach that is unique for the content of the subject under consideration. The graphic design students described the creative process numerically in 613 phases, which summarized all the main phases from planning and development to the final realization (Botella et al, 2018). They use very different levels of personal commitment when describing the phases. Only 4 students write personally in the 1st person singular, sometimes personally in the 1st person plural, while the rest respond in the 2 nd person singular or even in the passive form (recognized in 5 students). When students describe their creative process on paper, they are generally more personal, use more descriptive words (adjectives), list more phases involved in the process compared to the self-assessment of the process carried out with on-line tools. The latter points to an interesting phenomenon that we would like to investigate more closely in the future. Only two students recognized a high degree of abstraction in written and descriptive expression at the beginning of the semester, which, in our opinion, indicates the inclusion of higher-level cognitive processes (according to the taxonomy of Bloom - analysis, synthesis, creation). In other students we found a lower level of abstraction, which on average decreased when using on-line tools for self-assessment of their creative process. Here again, it would be worthwhile to explore (in further research) more closely at how the self-assessment tool used by the student affects written and sketchy expression. In five of the seven students we found a very high level of agreement between the quality (rating) of the final 3D product created during the semester and the level of the written and sketchy definition of the creative process and self-evaluation of the results of 3D work. In the case of two students, however, a greater discrepancy was found, which in our opinion indicates a disharmony between their processes of understanding and conception (both of oneself as the creator and of the 3D product), technical skills and visualization skills. The latter would of course need to be further explored with more in-depth psychometric methods.

With regard to the spatial visualisation tests conducted before and after the semester, we can state that the choice of elective course means that students have certain spatial abilities. Many of them have also completed the 3D modelling course in their basic studies. Therefore, the results of the first test, which was also easier, were better than the results of the second test. Nevertheless, we found that the students' spatial skills did not improve dramatically. 


\section{CONCLUSIONS}

It is expected that students that have chosen the subject "Advanced computer 3D graphic and visualisations" would have higher spatial abilities. "Internal imaging" is crucial for planning, modelling and to implement complex 3D visualisatons. Students have to communicate ideas verbally and visually as well, therefore visualisation skills are crucial. In our research we analysed, evaluated and synthesized information from written and visualised information gained from students.

The results show that the creative process is understood by the students as an intimate and very subjective choice of an individual, which is slightly altered by the educational process and in our case especially by the design process of 3D animation. The analysis of the students' definitions and the illustrations of the semantics of creative processes show the similarities of the answers before the educational process, where formulations such as "inner fulfilment", "idea formation", "creative aspiration" were used and simpler sketches were drawn. At the end of the semester, the definitions included phrases such as "achieving results", "transferring what has been created to a user" and "product display". Through the results of the spatial visualisation test, we also found that the course did not significantly improve students' spatial visualisation skills, which encouraged the educators to alter the curriculum towards more specific 3D content creation that would allow for improved spatial visualisation skills.

\section{REFERENCES}

[1] Alias, M., Black, T. R., Gray, D. E.: "Effect of Instructions on Spatial Visualisation Ability in Civil Engineering Students", International Education Journal 3 (1), 1-12, 2002.

[2] Botella, M., Glaveanu, V., Zenasni, F., Storme, M., Myszkowski, N., Wolff, M., Lubart, T.: "How artists create: Creative process and multivariate factors", Learning and Individual Differences 26, 161-170, 2013. doi: 10.1016/j.lindif.2013.02.008.

[3] Botella, M., Zenasni, F., Lubart, T. I.: "A dynamic and ecological approach to the artistic creative process in arts students: an empirical contribution", Empirical Studies of the Arts 29 (1), 17-38, 2011. doi: 10.2190/EM.29.1.b.

[4] Botella, M., Zenasni, F., Lubart, T.: "What Are the Stages of the Creative Process? What Visual Art Students Are Saying", Frontiers in Psychology 9, article 2266, 1-12, 2018. doi: 10.3389/fpsyg.2018.02266.

[5] Carson D. K.: "Encyclopedia of Creativity", (Academic Press, New York, 1999.), pages 395-402.

[6] Gardner, H.: "Frames of Mind: The Theory of Multiple Intelligences", (Basic Books, New York, 2011.), pages 179-216.

[7] Linn, M. C., Petersen, A. C.: "Emergence and characterization of sex differences in spatial ability: A meta-analysis", Child Development 56(6), 1479-1498, 1985. doi: 10.2307/1130467.

[8] McGee, M. G.: "Human spatial abilities: Psychometric studies and environmental, genetic, hormonal and neurological influences", Psychological Bulletin 86, 899-918, 1979. doi: https://doi.org/10.1037/0033-2909.86.5.889.

[9] Norman, K. L.: "Spatial visualization - A gateway to computer to computer-based technology", Journal of Special Education Technology 12 (3), 195-206, 1994. doi: 10.1177/016264349401200303

[10] Patkin, D., Dayan, E.: "The intelligence of observation: improving high school students' spatial ability by means of intervention unit", International Journal of Mathematical Education in Science and Technology 44(2), 179-195, 2013. doi: 10.1080/0020739X.2012.703335.

[11] Roslan, R. K., Ahmad, A.: "3D Spatial Visualisation Skills Training Application for School Students Using Hologram Pyramid", International Journal on Informatics Visualization 1 (4), 170-174, 2017. doi: 10.30630/joiv.1.4.61.

[12] Runco M. A., Dow G.: "Encyclopedia of Creativity", (New York, NY: Academic Press, 1999.), pages 433-435.

[13] Sorby, S. A.: "Spatial abilities and their relationship to effective learning of 3-D solid modeling software", The Engineering Design Graphics Journal 64 (3), 30-35, 2000. 


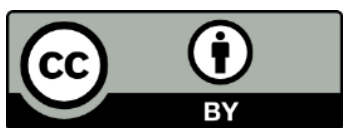

(C) 2020 Authors. Published by the University of Novi Sad, Faculty of Technical Sciences, Department of Graphic Engineering and Design. This article is an open access article distributed under the terms and conditions of the Creative Commons Attribution license 3.0 Serbia

(http://creativecommons.org/licenses/by/3.0/rs/). 